\title{
Qualitative comparison of north-american procedures for areawide pedestrian travel measurement
}

\author{
Ryan Greene-Roesel ${ }^{1}$; Mara Chagas Diógenes ${ }^{2}$; David R. Ragland ${ }^{3}$; Luis Antonio Lindau ${ }^{4}$
}

\begin{abstract}
There is no standard system for estimating area-wide pedestrian volumes in the United States. As a result, pedestrian volumes cannot be routinely used to guide transportation investments and monitoring measures performance. Vehicle volumes, by contrast, are measured systematically in each state and are reported to the Federal Highway Administration annually to be used in the allocation of federal funds. This paper investigates the advantages and disadvantages of three approaches to the creation of a standard system of pedestrian volume measurement: direct sampling, survey methods, and modeling. Examples of each method are given, and the potential of each to become a national standard is discussed. Of the three approaches, the modeling methods were judged to be most suitable for tracking pedestrian volumes at the national, state, and sub-state level. A standardized pedestrian volume modeling method could make use of existing data sources without generating the need for a new national pedestrian data collection effort.
\end{abstract}

\begin{abstract}
Resumo: Nos Estados Unidos não há um sistema padrão para estimar o volume de pedestres em áreas abrangentes. Como resultado, os volumes de pedestres não podem ser utilizados de forma sistemática na priorização da alocação dos investimentos no setor de transportes e para monitorar o desempenho das medidas adotadas. Por outro lado, volumes veiculares são mensurados sistematicamente em cada Estado e informados anualmente ao Federal Highway Administration para orientar a alocação de recursos federais. Este artigo investiga as vantagens e desvantagens de três métodos para a criação de um sistema padrão de mensuração do volume de pedestres: amostragem direta; amostragem por questionários e modelagem. São apresentados exemplos de cada método e discutido o potencial de cada um em se tornar um padrão nacional. O método de modelagem foi julgado o mais apropriado para determinar o volume de pedestres a nível nacional, estadual e municipal. Um método padrão baseado na modelagem de volumes de pedestres poderia utilizar as fontes de dados já existentes sem gerar a necessidade de um novo esforço de coleta de dados a nível nacional.
\end{abstract}

\section{INTRODUCTION}

"How much do people walk every year?" is a question that has yet to be answered in the United States. A number of data sources provide an incomplete answer. Vehicle volumes, by contrast, are monitored systematically throughout the nation. The Federal Highway Administration publishes an annual Highway Statistics Report that reports the vehicle miles traveled in each state, broken out by type of road system and by rural and urban areas. These volumes are used to allocate federal transportation funds to the states and for a variety of other purposes (FHWA, 2006). No equivalent measure exists for pedestrian volumes, although pedestrian travel is the second most common mode used for trips made in the United States ( $\mathrm{Hu}$ and Reuscher, 2004).

Part of the reason for the absence of a systematic

\footnotetext{
${ }^{1}$ Ryan Greene-Roesel, Traffic Safety Center, University of California at Berkeley, U.S. (e-mail: ryangr@berkeley.edu).

${ }^{2}$ Mara Chagas Diógenes, Programa de Pós-Graduação em Engenharia de Produção, Universidade Federal do Rio Grande do Sul. Porto Alegre, RS, Brasil (e-mail: maracd@producao.ufrgs.br).

${ }^{3}$ David R. Ragland, Traffic Safety Center, University of California at Berkeley, U.S. (e-mail: davidr@berkeley.edu).

${ }^{4}$ Luis Antonio Lindau, Programa de Pós-Graduação em Engenharia de Produção, Universidade Federal do Rio Grande do Sul. Porto Alegre, RS, Brasil (e-mail: lindau@producao.ufrgs.br).
} número 2, de dezembro de 2007. ISSN: 1415-7713. measure of pedestrian volumes lies in the complexity of pedestrian travel. Compared to vehicles, which tend to move in predictable ways along clearly defined routes, pedestrians are highly flexible in their route choice and can make numerous short stops and quick turns (Clifton and Krizek, 2004). Moreover, the pedestrian network is much more difficult to define than the vehicle network, as it can include numerous pathways and spaces not available to vehicles (Raford and Ragland, 2006).

Although the task of tracking pedestrian volumes presents a significant challenge, it is not insurmountable if resources and institutional support are provided on a par with vehicle volume tracking methods. This paper addresses the challenge of creating a method for measuring pedestrian volumes that parallels the method available for vehicle volumes. The method would, at a minimum, produce annual pedestrian volumes on the state and national level, and would ideally produce volumes linked to specific roadways.

Based on the literature, this paper explores three approaches to estimating area-wide pedestrian volumes that could serve as the basis for a national model: (i) direct methods, in which pedestrian activity is sampled at a representative set of sites throughout the area; (ii) surveys, in which a representative set of individuals in an area is asked to report its pedestrian activity; and (iii) modeling methods, which use some combination of direct counts, surveys, and secondary 
data to estimate pedestrian activity. Examples of each method are given, and the potential of each to become a national standard is discussed. It is important to note that this paper does not address methods of measuring pedestrian volumes at specific sites such as intersections and crosswalks.

\section{DIRECT METHODS}

To estimate pedestrian volumes in a geographic area through direct sampling it is necessary to develop a strategy to sample volumes systematically through time and space. The ideal estimate of annual pedestrian volumes in a city could be achieved by randomly sampling segments of the pedestrian network, such as sidewalks and crossings, throughout the city and throughout the year, including nights and weekends. To adequately represent the pedestrian network, enough samples would be required to account for volume fluctuations through both time, e.g. seasonal variations in pedestrian activity, and through space (Schwartz and Porter, 2000). As with any approach to estimating pedestrian volumes, data collection would need to occur on a regular basis to allow trends in pedestrian activity to be followed over time.

The direct sampling approach to measuring pedestrian volumes has some distinct advantages. Direct measurements of pedestrian activity are based on real observations, rather than reported behaviors, so they avoid the problem of under-reporting of short pedestrian trips common to surveys (Schwartz and Porter, 2000). Direct measurements capture the activity of all pedestrians at the sampled site, regardless of age or economic status, although they do not capture the rich demographic information typically included in surveys. They allow the linkage of pedestrian activity to site-specific factors such as intersection design.

Despite these advantages, there are very few examples of direct measurement approaches. This may be because of the lack of good inventories of the pedestrian network, which are necessary to devise a sampling scheme. Some jurisdictions, notably the New York Metropolitan Transportation Council (NYMTC), have instituted an annual program of sampling pedestrian volumes throughout the region on the same, or similar, sampling days so that volumes at the sampled sites can be compared (Schneider et al., 2005). High costs limited the frequency and extent of the counts, and there was no indication that the NYMTC expanded these samples to an annual volume for the region (Cerreño and Nguyen-Novotny, 2006).

Another attempt to devise a systematic pedestrian sampling program has been devised by the Institute of Transportation Engineers Pedestrian and Bicycle Council, with the assistance of Alta Planning and De- sign. This effort, known as the National Pedestrian and Bicycle Documentation Project, aims to establish a nationally consistent methodology for performing pedestrian and bicycle counts; to promote the performance of counts on official counting days during the second week of September; and to input counts into a national database (Alta Planning and Design, 2006). At the current time, the project is valuable in comparing pedestrian volumes at selected sites, but is not as useful for comparing area-wide pedestrian volumes, since the counts are not systematically collected throughout the nation. Given its voluntary nature, the project is unlikely to generate systematic pedestrian counts. This project is still under development and, so far, no specific methodology has been agreed and proposed.

The best example of direct volume sampling comes from outside the pedestrian realm. The Federal Highway Administration has developed a Traffic Monitoring Guide to aid states in the systematic sampling of vehicle volumes. The guide describes a method for sampling every roadway section at least once within a six-year period, and for converting a point-measure of volume (Average Daily Traffic) into a distance-based measure (Vehicle Miles Traveled) based on the length of the roadway segment (FHWA, 2001). Although many states use the methods in the Traffic Monitoring Guide, some states, such as California, use a combination of direct counts and modeling to estimate vehicle volumes (Caltrans, 2005).

The apparent lack of effort to measure pedestrian travel by sampling pedestrian activity over a broad area may be due to several complicating factors. It is much more difficult to devise a systematic sampling scheme of the pedestrian network than it is to devise such a scheme for the vehicle network due to complex characteristics such as the indefinite number of entrances onto the network and the existence of off-road pathways.

Another obstacle to the direct counting of pedestrian activity is related to the fact that automated pedestrian counting methods are not widely used and none of the available automated counting devices completely serves the purpose of detecting and counting pedestrians. There are many automated devices available that detect, count and classify motor vehicles (Dharmaraju et al., 2001; Schneider et al., 2005). The most common method of counting pedestrians is manual counting. Randomly sampling pedestrian volumes using manual methods can be a difficult task because field observers face difficulty in counting pedestrians at certain times (nights and weekends) and in certain locations (unsafe or inaccessible areas) (Schwartz and Porter, 2000; Schneider et al., 2005). 


\section{SURVEYS}

Unlike direct sampling methods, surveys conducted at the local, state, and national level are commonly used to quantify pedestrian activity over wide geographic area. Because surveys are able to capture detailed pedestrian characteristics and preferences, they are very useful for studying the pedestrian behavior of specific groups. Surveys are also able to capture detailed trip characteristics such as the number and length of walking trips made by an individual.

In direct sampling, by contrast, it is very difficult to determine the origin and destination of each pedestrian trip, or to determine detailed pedestrian characteristics. However, surveys have certain weaknesses. Surveys do not generally link pedestrian activity to specific infrastructure, such as roadway or sidewalk width, so it is difficult to determine the relationship between infrastructure and pedestrian activity from surveys alone. It is also difficult to determine whether the walking trips reported on surveys were made in areas where the pedestrian was exposed to traffic. Lastly, walking trips are commonly underreported in surveys, because individuals do not always remember short walking trips (Schwartz and Porter, 2000). For example, individuals may not report walking to access transit as a separate trip.

Survey data is available for many different types of geographies and time periods. When seeking information about pedestrian exposure over a wide area, it is important to know whether relevant survey data has already been collected. For that reason, this section focuses on describing existing pedestrian-related surveys and the type of information available from each. Three types of existing surveys are identified and evaluated: (i) health related surveys; (ii) travel surveys; and (iii) work related surveys. These characteristics are also summarized in Table 1.

There will be cases where existing surveys will not always meet the data needs of the user. For example, there is no existing data source that provides an estimate of pedestrian exposure to traffic for the state of California as a whole on a frequent basis. In these cases, institutional support and resources are needed to implement more frequent or new data collection efforts.

\subsection{Health related surveys}

Health surveys aim to track health conditions and risky behaviors. Since walking is a form of physical activity, some of these surveys include walkingrelated questions, which tend to be focused on whether the respondent obtained a healthy amount of physical activity. Therefore, these types of surveys may not contain information on the exact amount of walking or whether walking took place in areas where pedestrians were exposed to traffic. For example, the California Department of Health Services and the California Department of Transportation sponsored the Pedestrian Characteristics in California Survey in 2003 in order to track health trends. The survey included a question on the amount of time spent walking in a typical week (Schneider et al., 2005). Because the survey is not conducted on a regular basis, it is limited in its ability to track pedestrian volume trends over time, and it does not provide information about the total amount of exposure to traffic.

The Behavioral Risk Factor Surveillance System (BRFSS), an annual telephone survey administered by the Centers for Disease Control, is conducted annually. It includes questions on physical activity, but does not distinguish between walking and other forms of physical activity (BRFSS, 2006). The states could choose to add additional questions to the BRFSS in order to gain information about walking rates in the state.

\subsection{Travel surveys}

Travel surveys are conducted at the metropolitan, state, and national level for transportation planning purposes. Most rely on travel diaries, in which respondents record detailed information about trips taken during a designated travel period. The detail provided by travel diaries is valuable in estimating pedestrian volume, because it allows volume to be expressed in terms of the amount of time walked, the distance walked, or the number of walking trips made.

The largest travel survey conducted nationally is the

Table 1. Characteristics of existing pedestrian related surveys

\begin{tabular}{|c|c|c|c|}
\hline Survey & Walking Question & Geographies & Years available \\
\hline Decennial Census & Usual mode to work & Census tract $\rightarrow$ nation & 1980, 1990, 2000 \\
\hline American Community Survey & Usual mode to work & Census tract $\rightarrow$ nation & Every year after 2003* \\
\hline $\begin{array}{l}\text { Behavioral Risk Factor Surveillance } \\
\text { System }\end{array}$ & $\begin{array}{l}\text { None } \\
\text { ( It is possible to add on) }\end{array}$ & States, nation & Every year \\
\hline National Household Travel Survey & $\begin{array}{l}\text { Number, length, duration of } \\
\text { walk trips }\end{array}$ & Census divisions, nation & $\begin{array}{l}\text { Every } 6 \text { years: } 1969,1997, \\
\text { 1983, 1990, 1995, } 2001\end{array}$ \\
\hline California State Travel Survey & $\begin{array}{l}\text { Number, length, duration of } \\
\text { walk trips }\end{array}$ & $\begin{array}{l}\text { CalTrans Districts, state of } \\
\text { California }\end{array}$ & Every 10 years \\
\hline Metro Area Surveys & $\begin{array}{l}\text { Number, length, duration of } \\
\text { walk trips }\end{array}$ & SF, La \& Sac metro area & $\begin{array}{l}\text { Varies -about every 6-10 } \\
\text { years }\end{array}$ \\
\hline
\end{tabular}

*ACS release schedule varies by geography; data at the census tract level not available until 2010 
National Household Travel Survey (NHTS). The survey is conducted about every six years by the Federal Highway Administration, and records the travel patterns of about 20,000 randomly selected U.S. households. The NHTS reports the number of trips by mode that respondents took in the week the survey was administered. It can be used to quantify pedestrian trips as a share of all trips taken nationally or by major Census division (e.g. Mountain; Pacific, West South Central, etc.). The NHTS is not intended for use at the state or sub-state levels, but states or metropolitan areas can purchase add-ons (NHTS, 2001).

Several states and metropolitan areas also conduct travel surveys to serve local needs (TRB, 2006). In the state of California, travel surveys are conducted in several metropolitan areas and on at the state level. The California Statewide Household Travel Survey (CSTS) a travel survey of 17,040 households throughout California, was conducted between 20002001 by the California Department of Transportation (Caltrans). The CSTS quantifies the number, duration, and approximate distance of trips taken by survey respondents on an average weekday for each mode of transportation. It also captures household demographic and economic characteristics. The CSTS provides a robust estimate of the amount of pedestrian activity in the state of California, and for 17 sub-state regions, for the year 2000. The survey must be used cautiously or not at all for small geographic areas such as cities or counties as most collected data refer to metropolitan areas (Caltrans, 2002). In addition, the CSTS cannot be used to track short-term trends in pedestrian activity because it is not conducted on a regular basis.

Several metropolitan areas in California also collect travel surveys similar to the CSTS and the NHTS. For example, the Metropolitan Transportation Commission conducts the Bay Area Travel Survey (BATS) a study of the travel patterns of approximately 15,000 Households in the 9-county Bay Area. The BATS was conducted in 2000, 1996, 1990, 1981, and 1965. The Sacramento Area Council of Governments and the Southern California Association of Governments also conduct travel surveys about once a decade.

\subsection{Work related surveys}

The Journey-to-Work component of the U.S. Decennial Census long form contains detailed information about the work-trip characteristics of one in six U.S. households. Respondents are asked about the location of their workplace; their usual means of transportation to work; and the amount of time it usually took them to get to work. The data is free to the public, available online, and covers large and small geographies throughout the nation.
However, Journey-to-Work data has some limitations. The survey questionnaire asks only about which mode of transport the respondent used most frequently to commute to work in the previous week. By doing so, it accounts only for work trips, which make up a minority of all walking trips (Komanoff and Roelofs, 1993), and for employed adults, who make up less than half of the population (U.S. Census Bureau, 2004). Moreover, the form asks how the respondent "usually" got to work, and thus does not capture occasional trips to work made by another mode. Neither does it account for walking trips made as a component of the work trip, such as trips to and from a bus stop. This is because the survey questionnaire asks the respondent to name only the mode they used for the majority of the distance of their trip (U.S. Census Bureau, 2005).

In spite of these weaknesses, Census Journey-toWork data has been used as proxy for pedestrian exposure because it provides some information about how much people are walking in an area, and is often the only data on walking available at the level of the city. One widely-known report on pedestrian safety, which was published by the Surface Transportation Policy Project, used the percentage of people walking to work and population data from the Census to compare pedestrian risk in metropolitan areas across the nation (STPP, 2002; 2004).

The Census long form that provides Journey-toWork data is currently being replaced by a new product called the American Community Survey (ACS). Although the information being collected in the ACS is the same as what was collected in the Census long form, and thus still limited for not including other than journey-to-work trips, the two surveys differ in ways that have interesting implications for transportation planners and engineers. The most important difference is that Journey-to-Work data will be available every year through the ACS, rather than once a decade. Another important difference lies in the sample design. Whereas the Census long form data was collected during a specific week in April, the ACS samples households on a rolling basis during each month of the year. This means that ACS data will reflect traveler behavior throughout the year rather than for a specific season. When fully implemented, the ACS will sample about 3 million, or 1 in 10, U.S. households annually.

ACS data are currently available for communities of 65,000 inhabitants or more on a yearly basis. For smaller communities, it will take between several years to accumulate enough samples to provide data. Beginning in 2008, yearly estimates based on three year averages will be available for communities of 20,000 or more, and beginning in 2010, yearly estimates based on five-year averages will be available at 
the Census tract and block group level.

\section{MODELING METHODS}

Mathematical models can be used to estimate pedestrian volumes by combining key assumptions with existing data. If properly calibrated and tested, models can be powerful tools in estimating pedestrian volumes when direct measurement is not feasible. The advantages and disadvantages of modeling depend to some degree on the model itself, but in general, models have the potential to save time and resources without compromising the quality of the results. Raford and Ragland (2006) identified three main types of models: (i) sketch plan models; (ii) network analysis models; and (iii) microsimulation models.

\subsection{Sketch plan model}

Sketch plan models use available data to estimate pedestrian volumes for regional or city-wide planning purposes. These models rely on known or estimated correlations between pedestrian activity and adjacent land uses, such as square feet of office or retail space, and/or indicators of transportation trip generation such as parking capacity, transit volumes, or traffic movements (Schwartz et al., 1999). Some of these models are not capable of producing pedestrian volumes, but rather produce a dimensionless indicator of pedestrian activity, mapping the potential pedestrian demand. Sketch plan model are advantageous for using available data and presenting relatively low cost. The main disadvantage of such models remains in the fact that they are not able to assign realistic pedestrian volumes to specific streets or intersections.

The city of Sacramento, California, recently used a sketch plan method developed by Fehr and Peers Transportation Consultants (2005) as part of its pedestrian master plan. The method inputs demographic, economic and land use variables associated with walking into a Geographic Information Systems software to produce a dimensionless "pedestrian demand index" for each street segment in the city. The pedestrian demand index is composed by 16 indicators correlated with higher rates of walking, grouped into four categories: (i) need, (ii) proximities, (iii) walking environment, and (iv) important policy boundaries. The final index is calculated using a weight and value for each indicator.

\subsection{Network analysis model}

Network analysis models are more complex than sketch plan models because they rely on a map or model of the pedestrian network. As a result, they are capable of estimating volumes for specific street segments and intersections over an entire city or neighborhood. Although the models vary in tech- nique, most use a variation on the four-step modeling approach to generate and distribute trips based upon assumptions about the amount of walking trips in a study area and various route choice algorithms (BenAkiva and Lerman, 1985; Senevarante and Morall, 1986; McNally, 2000).

Raford and Ragland (2004) used a network analysis model, Space Syntax, to estimate pedestrian volumes on streets and intersections throughout Oakland, California. The model required input of a pedestrian route map derived from publicly available Census TIGER/line GIS centerline road maps; population and employment data from the U.S. Census and the California Economic Census; and raw pedestrian count data needed to calibrate the model. The model produced reasonable estimates of city-wide pedestrian volume, presenting a significant correlation between predicted and observed pedestrian volumes $(\mathrm{R} 2=$ 0.7717, $\mathrm{p}<0.001$ ).

The Space Syntax model is also useful for estimating pedestrian flow along corridors. This is very helpful because direct measurement of flow along corridors is difficult. It may be achieved by dividing the road network into small segments, such as a block length, and assuming that flow along the segment is constant. This is not always a fair assumption because of the complexity of pedestrian movement. For example, if a pedestrian is counted at the end of a block, it is uncertain whether he/she has been traveling for the entire block or if he/she just exited a building. With vehicle volumes, by contrast, it is often assumed that any vehicle passing through a point has been traveling along the length of the segment (FHWA, 2001). Space Syntax provides an alternative method of estimating flow along many corridors with a small set of samples as input.

\subsection{Microsimulation models}

Microsimulation models use flow principles from physical science to model pedestrian behavior in confined spaces such as the interior of shopping malls or subway stations, on a single or small number of streets, or within building interiors. These models provide highly accurate, detailed information about pedestrian movement, but require specialized software, knowledge and extensive data inputs (Raford and Ragland, 2006).

\subsection{Comparasion of modeling techniques}

Table 2 presents a comparison of the modeling techniques, highlighting their advantages and disadvantages for estimation of wide-area pedestrian volumes. This table was adapted from Raford and Ragland (2006). Each of the modeling approaches discussed in this paper is suited to a different scale of geographic analysis. Sketch plan models are best for broad re- 
Table 2. Comparison of modeling methods

\begin{tabular}{|c|c|c|c|}
\hline & Sketch Plan & Network Analysis & Microsimulation \\
\hline Scale of Application & Large scale (city, region, state) & Urban and neighborhood level & Individual Streets or intersections \\
\hline Advantages & $\begin{array}{l}\text { Little data collection required; } \\
\text { No specialized expertise needed; } \\
\text { Quick estimations. }\end{array}$ & $\begin{array}{l}\text { Good detail; } \\
\text { Reasonable accuracy; } \\
\text { Limited data requirements; } \\
\text { Appropriate to urban volume analysis. }\end{array}$ & $\begin{array}{l}\text { Highly accurate; } \\
\text { Detailed; } \\
\text { Allows visualization of pedestrian } \\
\text { flow. }\end{array}$ \\
\hline Disadvantages & $\begin{array}{l}\text { Aggregate level; } \\
\text { Low accuracy. }\end{array}$ & $\begin{array}{l}\text { Model must be calibrated with pedestrian } \\
\text { counts; } \\
\text { Requires existing GIS data; } \\
\text { Must be submitted to sensitivity test. }\end{array}$ & $\begin{array}{l}\text { Complex; } \\
\text { Steep learning curve; } \\
\text { Significant initial data require- } \\
\text { ments. }\end{array}$ \\
\hline
\end{tabular}

gional or statewide analysis; network analysis models are appropriate for corridor, neighborhood, or urban area analysis; and microsimulation models are best for a single street or smaller area.

Relevant literature indicates that sketch plans have potential to be put into standard use for estimating pedestrian volume throughout the country. While less accurate than other types of models, sketch plans are relatively simple to use and make the most out of existing data sources. A simple, standardized sketch plan method would be an improvement over the current absence of volume estimation methods in many areas.

Network analysis models have been successfully used to estimate pedestrian volumes in most large urban areas, but would be impractical in many small cities and rural areas that lack staffing and resources to perform the GIS analysis and calibration necessary to complete the model. Microsimulation models are much too complex and costly to be practical beyond the level of the street or intersection.

\section{DISCUSSION AND CONCLUSIONS}

This paper reviewed three possible systematic approaches to measurement of pedestrian volumes over wide areas. The choice of area wide counting methods depends on budget constraints and data needs, and the availability of existing data. The ideal approach would produce pedestrian volumes at the state and national levels on an annual or biennial basis. No single approach is best, but each has strengths and weaknesses, summarized in Table 3.
In the direct measurement approach, pedestrian volumes would be measured directly by manual observers or automated devices. For this method to be successful, a systematic annual sampling scheme would need to be devised and made mandatory for each state. No examples of systematic pedestrian volume sampling schemes capable of producing area-wide pedestrian volumes were found in this review, although such methods are frequently used to estimate vehicle volumes.

In the survey method approach, pedestrian volumes would be estimated through a survey that asks individuals to record their pedestrian activity over a specific time period. In order to apply this method widely, the survey sample size would need to be large enough to be statistically significant at the state level; the survey would need to target the entire pedestrian population; and it would need to be administered on an annual basis.

Many examples of surveys that estimate pedestrian volumes were found in this review; however, none meet the criteria listed previously. Several existing surveys can be used to measure pedestrian volume in specific times and places, as shown in Table 1. However no existing survey provides a measure of volume that can be used throughout the nation, because each is limited in its sample size, frequency, or by the type of question asked. If a single survey, such as the NHTS, were to be used to measure volume frequently and at small areas throughout the nation, it would require a large increase in funding. One possible lowercost solution would be for the federal government to

Table 3. Comparison of approaches to pedestrian volume estimation

\begin{tabular}{|c|c|c|}
\hline Approaches & Advantages & Disadvantages \\
\hline $\begin{array}{l}\text { Direct sampling } \\
\text { methods }\end{array}$ & $\begin{array}{l}\text { Based on real, not reported pedestrian activity; } \\
\text { All pedestrians at each site are sampled; } \\
\text { Pedestrian volumes linked to specific sites; } \\
\text { If designed appropriately, data could be aggregated from small } \\
\text { to large geographies. }\end{array}$ & $\begin{array}{l}\text { Difficult to devise a sampling scheme; } \\
\text { Would require significant manpower; } \\
\text { No demographic or attitudinal information captured; } \\
\text { No information on distance, length, or time walked; } \\
\text { No existing sampling scheme. }\end{array}$ \\
\hline Survey methods & $\begin{array}{l}\text { Can capture demographic and household data; } \\
\text { Can capture distance, length, and time walked; } \\
\text { Existing surveys could be adapted / expanded. }\end{array}$ & $\begin{array}{l}\text { Walk trips are consistently underreported in surveys; } \\
\text { Surveys generally only target adults; } \\
\text { Very large, costly sample size required. }\end{array}$ \\
\hline Modeling methods & $\begin{array}{l}\text { Make the most of available data; } \\
\text { Dynamic and flexible; } \\
\text { Potential for lowest cost. }\end{array}$ & $\begin{array}{l}\text { Different models may be needed for different geo- } \\
\text { graphic areas; } \\
\text { Output may be limited to dimensionless measure of } \\
\text { pedestrian demand. }\end{array}$ \\
\hline
\end{tabular}


coordinate all of the existing state and metro-area travel surveys so their results can be combined and compared. The NHTS could sample the remaining areas. Another strategy would be to investigate the relationship between work trips reported by the U.S. Census and all other walking trips. If work trips are found to be a good proxy for all other trips, the Journey-to-Work data could be adapted to estimate total pedestrian volume.

In the modeling approach, pedestrian volumes would be estimated using a combination of existing data and a limited amount of data collected through surveys or direct counts. A standard modeling scheme would need to be developed and adopted by all of the states. Many examples of pedestrian volume models were found in this review, as were models used to estimate vehicle volumes. However, no simple, standardized model exists at this time.

For any of the approaches outlined is this paper to be successful, a significant increase in resources devoted to pedestrian volume tracking and institutionalization of tracking would need to occur. However, the methods differ in the amount of resources that would be required. Any new large-scale data collection effort, such as an expanded National Household Travel Survey or a nationwide pedestrian volume sampling scheme, would probably be very costly. The least costly alternative would likely be the pedestrian volume modeling approach, which could combine existing data sources such as the Journey-to-Work Data from the American Community Survey with limited additional sample or surveys taken at the state level. Absent a major federal increase in funding for pedestrian volume tracking, simple modeling methods present the most promising alternative.

In the U.S., further research is still needed to identify and test a modeling method suited for use at the national, state, and sub-state levels, and to estimate the costs associated with operating the model. For other contexts, such as the ones prevailing in countries that do not yet have tradition in collecting and forecasting pedestrian volumes, this review can form the basis for constructing an appropriate methodology.

\section{REFERENCES}

Alta Planning and Design (2006) National Bicycle and Pedestrian Document Project. Alta Planning and Design, Inc. $<$ www.altaplanning.com/>. Accessed May 21, 2006.

Ben-Akiva, M. and S. Lerman (1985) Discrete Choice Analysis: Theory and Application to Travel Demand. The MIT Press, Cambridge, MA.

BRFSS (2006) National Center for Chronic Disease Prevention and Health Promotion. Behavioral Risk Factor Surveillance System. $<$ www.cdc.gov/brfss/about.htm>. Accessed June 30, 2006.

Caltrans (2002) California Statewide Household Travel Survey, 20002001. Final report. California Department of Transportation, Division of Transportation System Information.
Caltrans (2005) California Motor Vehicle Stock, Travel and Fuel Forecast. California Department of Transportation, Division of Transportation System Information.

Cerreño, A.L.C.de and M.L.H. Nguyen-Novotny (2006) Pedestrian and Bicyclist Standards and Innovations in Large Central Cities. Rudin Center for Transportation Policy \& Management, NYU Robert F. Wagner Graduate School of Public Service, and the Federal Highway Administration, in conjunction with the National Association of City Transportation Officials, Inc.

Clifton, K.J. and K.J. Krizek (2004) The Utility of the NHTS in Understanding Bicycle and Pedestrian Travel. National Household Travel Survey Conference: Understanding Our Nation's Travel. Transportation Research Board, Bureau of Transportation Statistics (BTS). Washington, D.C..

Dharmaraju, R., D.A. Noyce, and J.D. Lehman (2001) An Evaluation of Technologies for Automated Detection and Classification of Pedestrians and Bicycles. The 71st ITE Annual Meeting. Compendium of Technical Papers. Institute of Transportation Engineering, Chicago, IL.

Fehr and Peers Transportation Consultants (2005) City of Sacramento Pedestrian Master Plan: Making Sacramento the Walking Capital (Public Review Draft) City of Sacramento, Sacramento.

FHWA (2001) Traffic Monitoring Guide. Publication FHWA-PL-01-021. U.S. Department of Transportation, Federal Highway Administration, Office of Highway Policy Information.

FHWA (2006) About Highway Statistics. Federal Highway Administration, Office of Highway Policy Information, Washington, D.C. <www.fhwa.dot.gov/policy/ohpi/hss/abouthss.htm>. Accessed June 19, 2006.

Hu, P.S. and T.R. Reuscher (2004). Summary of Travel Trends: 2001 National Household Travel Survey. Federal Highway Administration , U.S. Department of Transportation.

Komanoff, C., and C. Roelofs (1993) The Environmental Benefits of Bicycling and Walking. National Bicycling and Walking Case Study No. 15. Publication FHWA-PD-93-015. Federal Highway Administration, U.S. Department of Transportation.

McNally, M.G. (2000) The Four-Step Model. In: D.A. Hensher and K.J. Button, Ed. Handbook of Transport Modelling. Pergamon, Oxford, United Kingdom, pp. 35-52.

NHTS (2001) Bureau of Transportation Statistics, U.S. Department of Transportation. National Household Travel Survey <nhts.ornl.gov/2001/index.shtml>. Accessed May 30, 2006.

Raford, N. and D.R. Ragland (2004) Space Syntax: Innovative Pedestrian Volume Modeling Tool for Pedestrian Safety. Transportation Research Record: Journal of the Transportation Research Board, No. 1878, TRB, National Research Council, Washington, D.C., pp. 66-74.

Raford, N. and D.R. Ragland (2006) Pedestrian Volume Modeling for Traffic Safety and Exposure Analysis: Case of Boston, Massachusetts. Transportation Research Board 85th Annual Meeting. CDROM. Transportation Research Board, Washington , D.C.

Schneider, R., R. Patton, J. Toole and C. Raborn (2005) Pedestrian and Bicycle Data Collection in United States Communities: Quantifying Use, Surveying Users, and Documenting Facility Extent. Federal Highway Administration, Office of Natural and Human Environment, U.S. Department of Transportation, Washington, D.C.

Schwartz, W. and C. Porter (2000). Bicycle and Pedestrian Data: Sources, Needs, and Gaps. Publication BTS00-02. Bureau of Transportation Statistics. U.S. Department of Transportation, Washington, D.C.

Schwartz, W.L., C. D. Porter, G. C. Payne, J. H. Suhrbier, P. C. Moe and W. L. Wilkinson III (1999) Guidebook on Methods to Estimate Non-Motorized Travel: Overview of Methods. Publication FHWA-RD-98-165. Federal Highway Administration, U.S. Department of Transportation, Washington, D.C.

Senevarante, P. and J. Morall (1986). Analysis of Factors Affecting the Choice of Route of Pedestrians. Transportation Planning and Technology, Vol. 10, No. 1, pp. 147-159.

STPP (2002) Mean Streets. Surface Transportation Policy Project, Washington, D.C.

STPP (2004) Mean Streets 2004: How Far Have We Come? Surface Transportation Policy Project, Washington, D.C.

TRB (2006) Household Travel Surveys on the WWW. Committee on Urban Transportation Data and Information Systems (ABJ30). Transportation Research Board <trb.mtc.ca.gov/urban/hhsurvey.html>. Accessed July 17, 2006. 
United States Census Bureau (2004) American Community Survey. Tables generated using American FactFinder. <factfinder.census.gov> Accessed July 17,2006.

United States Census Bureau (2005) American Community Survey 2005 Questionnaire.

$<$ http://www.census.gov/acs/www/Downloads/SQuest05.pdf > . Accessed May 30, 2006. 